\title{
ОЦЕНКА РАЗЛИЧНЫХ ПОДХОДОВ В ПРОФИЛАКТИКЕ ОККЛЮЗИИ ЛУЧЕВОЙ АРТЕРИИ ПРИ ВЫПОЛНЕНИИ ТРАНСРАДИАЛЬНЫХ ЛЕЧЕБНО-ДИАГНОСТИЧЕСКИХ КОРОНАРНЫХ ВМЕШАТЕЛЬСТВ В РАННЕМ И ПОЗДНЕМ ПОСЛЕОПЕРАЦИОННОМ ПЕРИОДЕ
}

\section{EVALUATION OF DIFFERENT APPROACHES IN PREVENTION OF RADIAL ARTERY OCCLUSION DURING TRANSRADIAL THERAPEUTIC AND DIAGNOSTIC CORONARY INTERVENTIONS \\ IN THE EARLY AND LATE POSTOPERATIVE PERIOD}

N. Peskov

Summary. This research study identifies the most effective method for preventing radial artery injury during diagnostic coronary angiography and coronary intervention. The hospital was divided into 3 groups. It has been proven that the use of controlled compression of the radial artery with the help of special bracelets was especially effective in contrast to the other two methods of protection.

Keywords: radial artery occlusion, TR-Band, medical and diagnostic coronary interventions.
Песков Николай Андреевич

Аспирант, ФГБОУ ВО «Ростовский Государственный Медицинский Университет» Министерства здравоохранения Российской Федерации, г. Ростов-наДону

nap_medic@bk.ru

Аннотация. Данное научное исследование выявляет наиболее эффективный метод профилактики повреждения лучевой артерии при выполнении диагностической коронароангиографии и чрезкожного коронарного вмешательства. Данные больные были разбиты на 3 группы в зависимости от выбранного метода профилактики повреждения лучевой артерии. Нами было доказано, что использование контролируемой компрессии лучевой артерии специальными браслетами, оказалось наиболее эффективно в отличие от двух других методов профилактики.

Ключевые слова: окклюзия лучевой артерии, TR-Band, лечебно-диагностические коронарные вмешательства.

\section{Актуальность темы исслеАования}

B рентгенэдоваскулярной и кардихирургической практике пациенты с различной коронарной патологией встречаются достаточно часто. Они нуждаются в интенсивном кардиохирургическом лечении. Однако, единственным эффективным методом диагностики проблем с коронарными артериями у больных, является диагностический метод «коронарография» [1,2]. Данный метод позволяет точно определить место повреждения коронарной артерии и определить дальнейшую тактику лечения данных больных. Этот диагностический метод выполняется преимущественно через пункцию лучевой артерии. Однако при выполнении коронарографии, может встать вопрос о немедленном выполнении больному операции в объеме стентирования участка пораженной артерии или же о выполнении данной операции после дообследования больного и стабилизации его состояния. Все это решается индивидуально[3,4]. Однако, при выполнении повторной операции по стентированию коронарной используют туже лучевую артерию и тут возникают проблемы, в связи с окклюзией лучевой артерии после выполнения предыдущего диагностического исследования [5]. Данная работа раскрывает различные подходы к предупреждению окклюзии лучевой артерии, такие как: 1) Использование гепарина совместно с препаратами, уменьшающими вазоспазм. 2) Ипсилатеральная временная окклюзия локтевой артерии. 3) Использование контролируемой компрессии лучевой артерии специальными браслетами.

Перед рентгенэдоваскулярными хирургами стоит не простая задача в сохранении нормально функционирующей лучевой артерии, в связи с тем, что после установки стента в коронарную артерию, больному кроме приема антиагрегантов также необходимо проведения повторного диагностического исследования «коронаро- 
Таблица 1. Клинико-демографическая характеристика исследуемых пациентов

\begin{tabular}{|l|l|l|} 
Характеристика & $\begin{array}{l}\text { Показатели } \\
\text { Абсолютный } \\
\text { показатель }\end{array}$ & Процентное соотношение \\
\hline Возраст, лет $(\mathrm{M} \pm \mathrm{SD})$ & $59 \pm 6,8$ & \\
\hline Мужской пол & 650 & $65,0 \%$ \\
\hline Женский пол & 350 & $35,0 \%$ \\
\hline Ожирение & 27 & $27,0 \%$ \\
\hline Гиперхолистеринемия & 358 & $35,8 \%$ \\
\hline ФВ левого желудочка & $57,6 \pm 6,8$ & \\
\hline Гипертония & 770 & $77,0 \%$ \\
\hline Диабет сахарный & 220 & $22,0 \%$ \\
\hline Атеросклероз различных систем & 189 & $18,9 \%$ \\
\hline Курение & 340 & $34.0 \%$ \\
\hline
\end{tabular}

графии» для контроля состояния коронарных артерии и функции самого стента, после его установки [6].

\section{Цель работы}

Основная цель данного научного исследования выявить наиболее эффективные методы профилактики окклюзии лучевой артерии при выполнении трансрадиальных лечебно-диагностических коронарных вмешательств, выбрав из трех методов профилактики окклюзии лучевой артерии наиболее эффективный и безопасный.

\section{Клиническая характеристика исслеАуемых пациентов}

Клинико-демографические особенности исследуемой кагорты пациентов представлены в таблице номер 1. Сред-

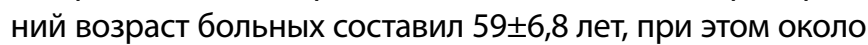
2/3 больных были мужского пола. Для рассмотрения больные отбирались с диагнозом стенокардия напряжения второго класса (87,9\%). У большого количества пациентов данной когорты испытуемых в анамнезе была артериальная гипертензия (77.0\%). У части испытуемых в намнезе имело место такое заболевание как гиперхолестеринемия (35,8\%). Также у наших пациентов присутствовало: ожирение - 27,0\% испытуемых имели ожирение, присутствовал такой диагноз как сахарный диабет - у 22,0\% испытуемых был определен диагноз сахарный диабет 2 типа; курение -около трети испытуемых употребляли сигареты (34,0\%). У $1 / 3$ испытуемых был установлен атеросклероз сосудов в различных системах организма (30,1\%).

\section{Обязательные условия}

Применение в трех группах пациентов идентичных трансрадиальных 6F интродьюсеров с гидрофильной оболочкой Merit Medical Systems, США).
Выполнение УзДГ-сосудов верхней конечности на первые сутки, через 30 дней после выполнения лечебно-диагностического коронарного вмешательства.

В группе пациентов у которых проводилась временная компрессия области пункции лучевой артерии, использовались устройства для временной контролируемой компрессии (браслеты TR-Band Terumo Япония)

Всем пациентам при выполнении лечебно-диагностической коронароангиографии были использованы диагностические катетеры для левой и правой коронарных артерий с гидрофильным покрытием фирмы «Cordis» США.

\section{Материалы и метомы}

В промежуток с сентября 2016 года по декабрь 2019 года исследование проводилось на базах Кардиохирургического центра ГБУ РО « Ростовская областная клиническая больница», отделения хирургического лечения сложных нарушений ритма сердца и электрокардиостимуляции ГБУЗ СК «КККД» г. Ставрополь, отделения рентгенхирургических методов диагностики и лечения № 2 МБУЗ КДЦ « Здоровье», В общем объеме в исследовании участвовали 1000 человек(650 мужчин,350 женщин). При этом данное количество людей было распределено на 3 группы, от выбранного метода, который был использован для профилактики окклюзии лучевой артерии.

\section{Результаты и обсужление}

В первые сутки у больных, которым была произведена пункция лучевой артерии в типичном месте с последующим введением после установки трансрадиального 6F интродьюсера 3мл 0.5\% р-ра нитроглицерина и последующим наложением асептической давящей повязки на 24 часа по окончании выполнения коронаро- 
Таблица 2. Сравнительный анализ заинтересованной лучевой артерии по группам наблюдения

\begin{tabular}{|l|l|l|l|l|}
\hline Группы испытуемых & $\begin{array}{l}\text { Количество } \\
\text { испытуемых }\end{array}$ & $\begin{array}{l}\text { Процент окклюзии } \\
\text { на первые сутки }\end{array}$ & $\begin{array}{l}\text { Процент окклюзии } \\
\text { на 30 день }\end{array}$ & $\begin{array}{l}\text { Процент окклюзии } \\
\text { через } 1 \text { год. }\end{array}$ \\
\hline $\begin{array}{l}\text { Гепарин (5000 ЕД) }+ \\
\text { асептическая бинтовая давящая } \\
\text { повязка. }\end{array}$ & $330 ч е л$ & Зчел(0,91\%) & 4 4чел(1,21\%) \\
\hline $\begin{array}{l}\text { Ипсилатеральная временная } \\
\text { окклюзия локтевой артерии }\end{array}$ & 330чел & 2чел(0,61\%) & 4(1,21\%) \\
\hline $\begin{array}{l}\text { Контролируемая компрессии } \\
\text { лучевой артерии специальными } \\
\text { браслетами (ТR-Ваnd) после } \\
\text { введение 5000 ЕД гепарина. }\end{array}$ & 340чел & 2чел(0,58\%) & $1(0,29 \%)$ & $1(0,29 \%)$ \\
\hline
\end{tabular}

Примечание. Различие средних величин между группами оценивали по критерию Манна - Уитни, статистически значимыми считали различия при $\mathrm{p}<0,05$.

ангиографии. Окклюзия лучевой артерии произошла у трех пациентов, что составило меньше $1 \%$ от общего количества больных в данной группе пациентов в конкретном промежутке времени (ранний постоперационный период). Профилактика окклюзии лучевой артерии этим же способом в разные временные промежутки показала одинаковые результаты. Окклюзия лучевой артерии произошла у четырех человек, что составило $1.21 \%$ в каждой временной группе. В итоге, используя данный метод профилактики окклюзии лучевой артерии, получены результаты, при которых в разные временные промежутки окклюзия лучевой артерии произошла у 11 пациентов из общего числа пациентов данной группы, что составило $3.33 \%$

Рассмотрев вторую группу пациентов, в которой мы использовали в качестве основного метода профилактики повреждения лучевой артерии это проведение ипсилатеральной контролируемой окклюзии локтевой артерии, были получены следующие результаты. Окклюзия лучевой артерии произошла в первые сутки после выполнения трансрадиальной лечебно- диагностической коронарографии у двух человек из общего количества пациентов, что составило $0.61 \%$, такие же результаты были получены нами и через 30 дней после коронангиографии. Однако при исследовании полученных результатов в группе пациентов через 1 год после выполненной коронароангиографии, нами было получены результаты, при которых окклюзия ранее пунктрированной лучевой артерии произошла у четырех человек, что составило $1.21 \%$. В сумме окклюзия лучевой артерии в данной группе пациентов произошла у 8 человек от общего количества пациетов, что составило $2.44 \%$. Данный результат оказался меньше чем в группе пациентов, у которых использовалась компрессия лучевой артерии асептической давящей повязкой на 24 часа. В третьей же группе пациентов, у которых мы использовали временную компрессия лучевой артерии совместно с применением 0.5\% раствора нитрогицерина после установки трансрадиального интродьюсера 6F- окклюзия лучевой артерии возникла в первой временной группе у двух человек от общего числа пациентов в данной группе, в конкретном временном промежутке, что составило $0.58 \%$. В двух других группах, наши результаты оказались одинаковыми. При использовании данного метода профилактики окклюзии лучевой артерии, из общего количества пациентов данной группы, окклюзия лучевой артерии произошла у одного человека в каждом временном промежутке, что составило 0.29\%. При этом общее количество окклюзий лучевой артерии в данной группе произошло у четырех человек, что составило $1.16 \%$, что достоверно меньше относительно 1 и 2 группы ( $p<0,05)$.

Учитывая полученные нами результаты и проведенный нами сравнительный анализ трех методов профилактики окклюзии лучевой артерии после выполнения коронароангиографии и чрезкожного коронарного вмешательства, можно с достоверно говорить, что все три метода профилактики окклюзии лучевой артерии показали себя вполне дееспособными, что может говорить о том, что все три метода профилактики можно использовать. Однако наилучшие результаты оказались в группе, где использовалась временная контролируемая компрессия области пункции лучевой артерии специальными компрессионными устройствами (TR-Band). Поэтому использование данного метода профилактики окклюзии лучевой артерии, является наилучшим выбором у практикующих интервенционных хирургов.

\section{Зак^ючение}

Выполнение контролируемой компрессии места пункции лучевой артерии, доказало свое преимущество по сравнению с двумя другими методами профилактики 
таких как: использование гепарина совместно с препаратами, уменьшающими вазоспазм и ипсилатеральная временная окклюзия локтевой артерии. В обозримом будущем все больше кардиохирургов освоит технику лучебно-диагностического коронарного вмешательства трансрадиальным способом, что даст предпосылки для распространения методов профилактики окклюзии лучевой артерии, в связи с ее большой важностью, потому что работающая лучевая артерия важна не только после имплантации стента в коронарную артерию, а также для выполнения повторных, диагностических коронароангиографий. При этом лучевая артерия сама по себе представляет собой готовый аутрансплантат, который нужен для проведения аортокоронарного шунтирования. И также лучевая артерия является одним из важных доступов для выполнения прямого артериального давления в анастезиологической практике. И она же важна для большого числа больных, которым необходимо выполнение гемодиализа, являясь при этом необходимым пластическим материалом для создания артериовенозной фистулы. Современные рекомендации пока не полностью определили какой метод профилактики окклюзии лучевой артерии, является «золотым» стандартом. На сегодняшний день нет исследований, показывающих результаты при различных методах профилактики окклюзии лучевой артерии в различные временные промежутки. Несмотря на неопределенность какой метод лучше, в нашем исследовании нам удалось доказать, в трех группах испытуемых пациентов, что после вы- полнения трансрадиальной лечебно-диагностической коронароангиографии, наилучший метод профилактики окклюзии лучевой артерии, как в ранний послеоперационный период, так и через год после выполнение данного оперативного вмешательства это применение контролируемой компрессии лучевой артерии при помощи TR-band.

С учетом полученных результатов становится очевидным, что контролируемая компрессия лучевой артерии при помощи TR-band (специальные браслеты), является наилучшим методов профилактики в трех различных группах исследуемых пациентов. По всей видимости, применение всех трех методов профилактики лучевой артерии, показало себя с лучшей стороны, и можно применять все три метода, но самый лучший и наиболее эффективный метод-это контролируемая компрессия области пункции лучевой артерии при выполнении трансрадиального лечебно-диагностического коронарного вмешательства. Эту схему нужно внедрять после специального отбора с учетом всех полученных ранее клинических и ангиографических данных. Поскольку контролируемая компрессия является ключом к успеху в профилактике окклюзии лучевой артерии и это должен знать и применять интервенционный хирург в своей повседневной практике. Только сумма всех факторов для профилактики отдаленных причин окклюзии лучевой артерии, позволит добиться оптимальных результатов в этом вопросе.

\section{ЛИТЕРАТУРА}

1. Anderson S.G., Ratib K., Myint P. K., Keavney B., Kwok C. S., Zaman A., Ludman P. F., de Belder M. A., Nolan J., Mamas M. A. Impact of age on access site-related outcomes in 469,983 percutaneous coronary intervention procedures: insights from the British Cardiovascular Intervention Society/Catheter Cardiovasc Interv. 2015;86:965-972. [PubMed]

2. Feldman D.N., Swaminathan R.V., Kaltenbach L. A., Baklanov D.V., Kim L. K., Wong S.C., Minutello R. M., Messenger J.C., Moussa I., Garratt K. N., Piana R. N., Hillegass W. B., Cohen M. G., Gilchrist I.C., Rao S. V. Adoption of radial access and comparison of outcomes to femoral access in percutaneous coronary intervention/ the National Cardiovascular Data Registry (2007-2012). Circulation. 2013;127:2295-2306. [PubMed]

3. Kotowycz M.A, Johnston K.W, Ivanov J, Asif N., Almoghairi A. M., Choudhury A, Nagy C. D., Sibbald M., Chan W., Seidelin P.H., Barolet A.W., Overgaard C. B., Džavík V. Predictors of radial artery size in patients undergoing cardiac catheterization: insights from the Good Radial Artery Size Prediction (GRASP) study/ Can J Cardiol. 2014 Feb;30(2):211-6. doi: 10.1016/j.cjca.2013.11.021. Epub 2013 Nov 23.

4. А. Князев и др. // Груд. и сердечно-сосудистая хирургия.—2016. — № 4.— С. 207-213

5. Особенности применения антиагрегантной и антикоагулянтной терапии при разных вариантах гибридной реваскуляризации миокарда у пациентов пожилого и старческого возраста / Г. Г. Хубулава, К. Л. Козлов, С. С. Михайлов и др. // Успехи геронтологии. — 2013.— Т. 26, № 4.— С. 685-688.

6. Соколов М.Ю. и соавт. Реєстр перкутанних коронарних втручань: розширений порівняльний аналіз, реперфузійна терапія в Україні, Сервей ПКВ - 2015. // Серце і судини. — 2015.— № 3.— С. 7-29.

(c) Песков Николай Андреевич ( nap_medic@bk.ru ). 